\title{
American ecology at the crossroads
}

Faced with a hostile Congress, US ecologists must distance themselves from environmental activism, and perhaps adopt lessons learned in Britain.

Snowbird, Utah. "When many in our Congress attempt to overturn carefully crafted laws and regulations that protect our citizens from pollution and the looting of our natural heritage, they are... attempting to overturn a 500-year legacy of civilization that has steadily replaced superstition and irrationality with understanding of, and respect for, science".

It is language like this from the President's Men - in this case Mr Timothy Wirth, Under Secretary of State for Global Affairs - that has got Republican congressmen rattled (see page 453). Wirth could pull it off, as he was addressing the home crowd, at the 80th annual meeting of the Ecological Society of America in Snowbird on Tuesday last week (1 August). His words were balm to researchers bloodied by a Congress generally hostile towards their work. Ecologists are seen as enemies of the free market, whose work inevitably leads to oppressive regulations to protect endangered species and bar economic progress. The reaction of politicians is twofold: either they foster a culture of ignorance (in Wirth's words "what we don't know can't hurt us - or take responsibility for"), or they tar ecologists with the brush of environmental activism, emphasizing connotations of left-wing ecoterrorism, abrogation of the rights of private landholders, and frankly un-Christian moral laxity.

One victim has been the Biodiversity Treaty discussed at the United Nations conference at Rio de Janeiro two years ago. After much scholarly and political discussion, and having been passed by the Senate Foreign Relations Committee by 16 votes to 3 , it was derailed when a rightwing commentator produced a 75-page report evoking, in Wirth's words, "images of world governance, paganism, nature worship and a host of other nonsense". Ratification of the treaty by the United States seems to have been postponed indefinitely.

Salem is dangerously close, but if working ecologists are in the habit of lewd exhibition in the woods by night, ululating before graven images of Pan, they are surely joined by those notorious left-wing intellectuals former Presidents Ronald Reagan and George Bush: for another move seeks to reverse the Montreal Protocol on the emission of chlorofluorocarbons (CFCs), an agreement based on programmes of research into climate change encouraged by those two regulato- ry zealots. On the basis of reports by individuals who, according to Wirth, lack the appropriate expertise, Arizona has passed a law allowing the manufacture of CFCs.

Some elements in Congress are clearly having a field day. But if, to paraphrase Emerson, against stupidity the gods themselves contend in vain, how can ecologists here hope to stave off the oncoming fall of night?

The problem is more of public image than the research itself. Ecologists should distance themselves from unfocused environmental activism, promoting the kind of serious research that will make a positive difference to the health and wealth of the United States. People get the governments they deserve, but in the last congressional poll, few voted for polluted drinking water or the barbecuing of the last spotted owl. To this end, ecologists could learn from the British experience. In respect of governments with all eyes on the bottom line, the United Kingdom has 16 years' headstart on the current Congress (although to be fair, the British government, for all its myopia, has always been far less hostile).

Before Rio, the public perception of ecology in Britain was of synonymy with activism. At that time it was routine to see, at serious meetings, hirsute, madeyed men in chunky knitwear exhorting us to save the lesser swivel-eyed bandicoot (just substitute your favourite cuddly species here), and saying that all endangered species must be protected, no matter what. Although, even then, arguably only a minority struck such attitudes, their clear message attracted the most attention. The establishment response was one of indulgent sympathy, but ecologists got the message that these Rousseauesque fantasies, although noble, provided little guidance for the formulation of policy.

In response, organizations such as Greenpeace replaced rhetoric with research. Environmental protection became a respectable, mainstream concern: even the then Prime Minister, Mrs Margaret (now Baroness) Thatcher, was at pains to demonstrate her 'green' credentials.

Ecologists began to ask questions based on the assumption that, given realistic and finite budgets, hard choices had to be made. To inform such choices, they devised operational definitions for such hitherto nebulous terms as 'biodiversity', which would be useful in practical deci- sion-making. The league of hirsute, madeyed men was dislodged by a new breed of ecologists in coat and tie, no stranger either to differential equations of to the corridors of power. It is perhaps no accident that Professor Robert May of the University of Oxford, an ecologist of this stripe, is now the chief scientific adviser to the British government.

None of this is meant to imply that ecology is less rigorous in the United States than elsewhere. Rather, the poor public image of US ecologists among politicians, already inclined to hostility, makes changing their minds more difficult than it might otherwise be.

The first task is to counter, calmly but firmly, the continuing political campaign of misinformation. This already takes up much of the time of Dr Ron Pulliam, director of the National Biological Service (NBS). Formed less than two years ago from the research arms of the Fish and Wildlife Service and other bodies, the NBS is as endangered as the spotted owl and may yet go the way of Florida's dusky seaside sparrow (deceased 16 June 1987).

To the cynic, the formation of the NBS from bodies with more diverse functions looks like something set up only to be knocked down again. If the recipe for congressional cuts is a Shakespearean witches' gruel, thick and slab, the NBS falls too easily into the role of birth-strangled babe, ditch-delivered (in Republican eyes) by a drab.

The second task is to promote the kind of level-headed compromise not usually associated with activism. This attitude might be successfully applied to the Endangered Species Act, due for reappraisal in Congress. The likely damage, though, will surely be limited if ecologists can draw the congressional sting by making it plain that there are compromises they would be prepared to accommodate. Many ecologists clearly feel this way, but their message is not getting through.

Not that ecologists could not recruit a little outside help, perhaps from unlikely places. Members of the National Rifle Association, whose liberal views are so cleverly masked by their vocal assertion of their constitutional right to bear arms, should extend this to bearing them into uncut forests for the purposes of bagging abundant wildlife.

As every ecologist knows, selective pressure and habitat disturbance creates surprising bedfellows.

Henry Gee 